\title{
Remediation Models Used in a Pharmacy Calculations Course
}

Dana A. Strachan, PharmD

Lloyd L. Gregory School of Pharmacy, Palm Beach Atlantic University

\begin{abstract}
Remediation is a required component of pharmacy programs. In a pharmacy calculations course, two student-centered models of remediation have been utilized. These models were a shift from an intensive, hands-on infrastructure of faculty and student engagement to a more student self-directed process. The models utilized development of an individualized plan for each student, clearly outlined expectations, faculty availability for consultation, as well as flexibility in remote completion of the assigned activities. Both models resulted in student success.
\end{abstract}

Keywords: pharmacy calculations; remediation; remedial activities

\section{Description of the Problem}

Calculations is a critical component of the profession of pharmacy to help ensure the safe and accurate dispensing of medications to patients. In fact, the North American Pharmacist Licensure Examination (NAPLEX), which assesses minimal competency of pharmacy graduates as part of licensing provides competencies, focused on calculations in its blueprint in Area 2: Safe and Accurate Preparation, Compounding, Dispensing, and Administration of Medications and Provision of Health Care Products. ${ }^{1}$ As such, many pharmacy programs include a standalone course devoted to pharmacy calculations. In a 2007 survey of U.S. pharmacy programs with $81 \%$ of schools responding, Brown and colleagues determined that $88 \%$ of responding pharmacy programs teach a pharmacy calculations course in the first professional year with half of these being taught as standalone courses. ${ }^{2}$ It appears pharmacy programs are targeting early curricular instruction in pharmacy calculations to help pharmacy students build a solid foundation of mathematical skills as they matriculate through the program.

However, when investigators at a small, private pharmacy school evaluated the mathematical skills of their incoming first year pharmacy students, they learned that the average performance on the assessment, which included eighth grade levels domains and difficulty levels, was $68.90 \% .^{3}$ Furthermore, another study conducted in the United Kingdom concluded there was a lack of retention of fundamental mathematical concepts for incoming first year pharmacy students. ${ }^{4}$ These studies highlight the importance of ensuring pharmacy students are proficient in mathematical skills. In addition to teaching with the core curriculum, mechanisms are needed to support those pharmacy students who are unsuccessful in the area of pharmacy calculations.

Corresponding author: Dana A. Strachan, PharmD

Lloyd L. Gregory School of Pharmacy

Palm Beach Atlantic University

West Palm Beach, Florida

Email: dana strachan@pba.edu; Phone: 561-803-2734
Remediation policies are a requirement of the Accreditation Council of Pharmacy Education (ACPE) standards (Standard 17 - Progression) for pharmacy colleges and schools. ${ }^{5}$ However, ACPE has not prescribed the manner or format in which pharmacy programs must offer such remedial activities. Thus, pharmacy programs have been challenged to design a policy with programming and activities that best serves their students. These policies must be carefully balanced with workload expectations for both the student and the faculty.

Maize and colleagues defined educational remediation as "the act of providing a remedy to a problem or a process to correct an academic fault or deficiency." An estimated 6 to $15 \%$ of students in a health profession have reported academic difficulties. In turn, these difficulties may lead to withdrawal from the program, leaving them with significant debt. ${ }^{6}$ Therefore, as ACPE emphasizes, it is critical for the college/school to implement interventions for students that provide an opportunity to successfully resolve the area(s) of deficiency. ${ }^{5}$

At Palm Beach Atlantic (PBA) University, we revised our remediation policy (Table 1 ) shifting from a course-centric policy to one that is more student-centric. Although the policy and procedures mandate the inclusion of a comprehensive cumulative assessment of all course material, the policy allows for faculty to freely determine the format of remediation, including content delivery methods and assessments used for remedial activities. Remediation activities to be utilized may include, but are not limited to, self-study, direct instruction, group work, assignments, assessment, peer tutoring, or any combination of these activities. Of note, this policy only applies to required, didactic courses occurring in the first through third years of the program. Prior to the initiation of remediation, the course coordinator is required to develop a remediation plan that is tailored to the student's academic deficiencies, which must be approved by the department chair and signed off by the student and coordinator. The expectations and requirements for the student are clearly outlined in the plan. 
The Supplemental File contains a remediation plan template used in the pharmacy calculations course.

In this paper, remedial models used at PBA in a pharmacy calculations course will be described.

\section{Pharmacy Calculations Remediation Models}

During the fall semester of the first year of pharmacy school at PBA, students are required to take a 2 credit hour didactic course entitled Pharmacy Calculations. Throughout the course, students are given a total of 5 intra-semester examinations, each containing 10 open-ended math problems. As the student progresses through the course, each examination contains 8 questions on the new material and 2 questions on the old material. Thus, the students are engaged in a cumulative examination each time they are assessed in this course. The course concludes with a fully cumulative multiple-choice examination of 30 questions. Although homework assignments are given in the course, the assignments are not graded. Students are not required to turn in homework assignments unless their cumulative grade is less than $76 \%$. For students who score less than $70 \%$ (i.e. a passing grade) on any examination, the student is asked to evaluate each missed question, classify the deficiency, and rework each math question(s) that was/were missed. Two review sessions covering examinations from the last 2 years are given before each intra-semester examination.

Under the revised remediation policy, one student during year one and one student in year two were deemed eligible to remediate based on the policy. Eligibility criteria includes all of the following: a) only 1 didactic course failed during the semester, b) final grade average in failed course is not less than $65 \%$, c) the maximum of 3 remediated courses has not been met, d) student is not on academic or Professionalism and Honor Code probation, e) student demonstrated active participation during the semester. (Active participation in the curriculum is defined as a student who participates in class with regular class attendance, participation in the promediation process [i.e., an early intervention process to detect academic deficiencies] and assignments and utilization of available academic resources.)

\section{Example One}

Prior to initiation of remediation, this student's performance on all 5 intra-semester examinations was evaluated. As a small number of deficiencies related to one area were identified, a plan was developed to hone in on this area. Over the winter break, the student was required to: review all class notes and read assigned chapters in the required course textbook on the areas of deficiency, complete all assigned homework problems from the semester for the areas of deficiency, complete a minimum of 5 questions from a question bank (Qbank) per topic on the areas of deficiency, and complete assigned problems in another textbook on the areas of deficiency. The
Qbank is a resource that comes with the required course textbook (Ansel HC, Stockton SJ. Pharmaceutical Calculations. $15^{\text {th }}$ ed. Philadelphia, PA: Lippincott Williams \& Wilkins; 2016) and allows the student to design a practice examination on the desired topics. The student was able to submit evidence of performance to the coordinator. Although not formally graded, feedback was provided on the student's performance. For the remainder of the class (i.e., material that were not deemed an area of deficiency), the student was given the directive to review the class material as a whole. An opportunity to engage with the coordinator as needed through email, phone, electronic meetings, or in person, as warranted, was provided to the student. This student did not engage in any additional interactions with the coordinator and maintained a selfdirected process for approaching remediation.

In mid to late December, the student was given a "deficiency" examination in which 18 open-ended questions were given to the student that purely focused on the areas of deficiency. This assessment was weighted as $40 \%$ of the overall remediation grade. Immediately prior to the beginning of spring classes in January, the student was given a cumulative final examination containing 30 open-ended questions assessing all course material. A 30 question open-ended model was chosen, as it was similar to the 30 question cumulative final examination offered during the semester course; however, it contained all open-ended questions, allowing the coordinator to see the student's work and rationale behind the problem solving. This assessment was weighted as $60 \%$ of the overall remediation grade. A total performance score of $70 \%$ or higher between the two assessments was required in order for the remediation to be considered "successful". Based on this model, the student successfully completed remediation.

\section{Example Two}

The student was deemed eligible to remediate but had a broader scope of academic deficiencies. After reviewing the student's performance on all 5 intra-semester examinations, the individualized plan contained all of the same elements as the previous student's: reviewing class notes and readings, homework assignments and Qbank questions due for the areas of deficiency. Instead of providing a deficiency examination, $100 \%$ of the cumulative final examination containing 30 openended math problems was used to assess the student's performance in remediation. Similar to before, the student was required to earn at least $70 \%$ on this assessment. In order to satisfactorily complete remediation, the student was also required to submit the homework and Qbank assignments. The student initiated a phone call with the coordinator on one occasion to resolve some challenges with the material and to clarify expectations. Otherwise, the student was engaged in a self-directed process. The student successfully completed remediation of this course. 


\section{Discussion}

Remediation is a required component of pharmacy programs. ${ }^{5}$ Reflective consideration should be given to the model of remediation that students are offered to correct areas of deficiency.

Students receive full exposure to course material throughout any given didactic semester. However, their success might be jeopardized by personal circumstances, such as illness, family crises, or other significant life events, lack of time spent studying the material, inappropriate study methods, poor selfesteem and confidence, lack of support system, inadequate academic preparedness, lack of motivation, amongst other reasons. ${ }^{7}$ Therefore, remediation efforts are often viewed as a "second chance" and may be beneficial to students who are influenced by these factors given that these remedial activities are generally given at times (e.g., winter break, summer) when students are not carrying a full academic load and can fully focus on the material.

Designing and implementing a successful remediation program at the completion of teaching, facilitating, and/or coordinating a semester long course can be daunting. In the past at PBA, remediation was a course-focused process, and students were brought back during the summers to engage in a 3 to 4 week long remediation process. A minimum of 4 hours per day was spent interacting with the eligible students on campus, oftentimes re-teaching the material. Intensive sessions were conducted in which students created math problems of their own, involving a "teach back" method to the coordinator to ensure comprehension. At least 3 examinations were administered in this model. Homework and additional assignments were also required. Additionally, conducting remediation in the summer and requiring the student to physically be on campus for an extended period of time was a challenge, especially in light of the experiential portion of the curriculum, which is conducted during the summer months. While successful in most, but certainly not in all cases, this model was not sustainable given the amount of effort required in the execution of remediation and the schedule challenges this created. Thus, transitioning into a more self-directed process has greatly alleviated the workload and scheduling concerns. Additionally, it has not resulted in the expense of student success. Students are no longer required to be on campus for remediation, but are given other means of contacting the coordinator. Opening up the winter break for remediation allows for more immediate attention to be placed on the areas of deficiency without delaying the process until summer.

These two remediation models were similar yet different in their design. Both offered the same preparatory materials and assignments and the required component of a cumulative final examination. In Example One, there were specific deficiencies and it was easier to target those areas through a "deficiency" examination that was weighted into the student's overall performance for remediation. Given the broader scope of deficiencies with the student in Example Two, a "deficiency" examination would have appeared more like a cumulative final examination. Thus, a decision was made to only include one final examination totaling the entire grade for remediation. In both cases, the students were successful.

Anecdotal feedback suggests that students like the ability to navigate the material on their own schedules, especially as many travelled back home or to other destinations over the winter break. In recognition of the increased use of technology in academics, the use of the Qbank was received positively as students received immediate feedback on their performance. Having the flexibility to remotely complete assignments allowed students to wrestle with the material on their own before seeking guidance. One student shared the value of selfstudy in identifying additional areas of weakness that needed to be strengthened. This student also expressed appreciation for being given the opportunity to prove the ability to be successful.

Student success or lack thereof in pharmacy calculations remediation will continue to be collected and evaluated. At PBA, we have further engaged in remediation assessment more broadly to objectively determine the impact of remediation. Specifically, assessment efforts are being implemented towards best practices (i.e., format/logistics, activities) of remediation and whether remediation is a predictor of success or lack of success in the pharmacy program.

Although one remediation model certainly does not "fit all", the two similar structures used in this pharmacy calculations remediation were individualized and resulted in student success. Thus, it is possible to achieve successful remediation, while fostering an environment of student self-directed learning.

Acknowledgements: None

Conflicts of Interest: None

Funding Support: None 


\section{References}

1. NAPLEX ${ }^{\circledast} /$ MPJE$^{\circledR}$ Candidate Application Bulletin.

National Association of Boards of Pharmacy Web site.

https://nabp.pharmacy/wp-

content/uploads/2019/03/NAPLEX-MPJE-Bulletin-

March-2019.pdf. Accessed on May 23, 2019.

2. Brown MC, Hanggi A. Pharmaceutical calculations

instruction and assessment in US colleges and schools

of pharmacy. Am J Pharm Educ. 2007;71(5): Article

87. doi: 10.5688/aj710587.

3. Latif DA, Grill JA. Assessing the basic math skills of first-year doctor of pharmacy students. J Pharm Teach. 2002;9(2):17-25. doi: 10.3109/J060v09n02_02.

4. Malcolm RK, McCoy CP. Evaluation of numeracy skills in first year pharmacy undergraduates 1999-2005.

Pharm Educ. 2007;7(1):53-59. doi:

10.1080/15602210601084671.

5. Accreditation Council for Pharmacy Education. 2016.

Accreditation standards and key elements for the professional program in pharmacy leading to the Doctor of Pharmacy degree. Available at https://www.acpeaccredit.org/pdf/Standards2016FINAL.pdf. Accessed March 8, 2019.

6. Maize DF, Fuller SH, Hritcko PM, et al. A review of remediation programs in pharmacy and other health professions. Am J Pharm Educ. 2010;74(2):Article 25. doi: 10.5688/aj740225.

7. Cherif, AH, Adams G, Movahedzadeh F, Martyn MA, Dunning J. Why do students fail? Faculty's perspective. The Higher Learning Commission.

Chicago, IL; 2014. 